This item was submitted to Loughborough's Research Repository by the author.

Items in Figshare are protected by copyright, with all rights reserved, unless otherwise indicated.

\title{
The effects of initial conditions and takeoff technique on running jumps for
} height and distance

PLEASE CITE THE PUBLISHED VERSION

http://dx.doi.org/10.1016/j.jbiomech.2011.06.010

PUBLISHER

(C) Elsevier

VERSION

AM (Accepted Manuscript)

LICENCE

CC BY-NC-ND 4.0

\section{REPOSITORY RECORD}

Wilson, Cassie, Mark A. King, and Maurice R. Yeadon. 2019. "The Effects of Initial Conditions and Takeoff Technique on Running Jumps for Height and Distance”. figshare. https://hdl.handle.net/2134/8693. 
This item was submitted to Loughborough's Institutional Repository (https://dspace.lboro.ac.uk/) by the author and is made available under the following Creative Commons Licence conditions.

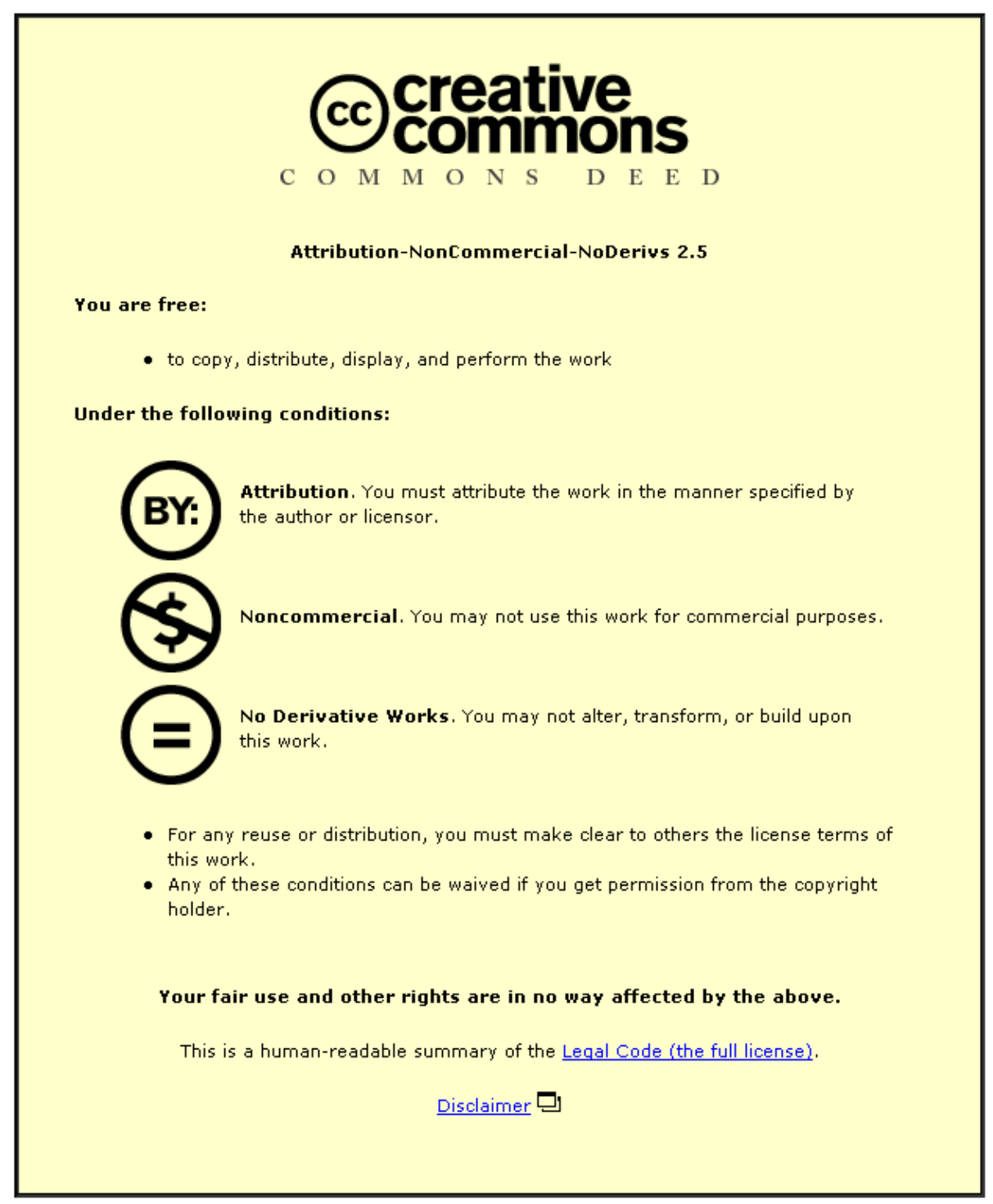

For the full text of this licence, please go to: http://creativecommons.org/licenses/by-nc-nd/2.5/ 


\title{
The effects of initial conditions and takeoff technique on running jumps for height and distance
}

\author{
Cassie Wilson $^{1}$, Mark A. King ${ }^{2}$ and Maurice R. Yeadon ${ }^{2}$ \\ ${ }^{1}$ Department for Health, University of Bath, UK. \\ ${ }^{2}$ School of Sport, Exercise and Health Sciences, Loughborough University, UK.
}

\begin{abstract}
This study used a subject-specific model with eight segments driven by joint torques for forward dynamics simulation to investigate the effects of initial conditions and takeoff technique on the performance of running jumps for height and distance. The torque activation profiles were varied in order to obtain matching simulations for two jumping performances (one for height and one for distance) by an elite male high jumper, resulting in a simulated peak height of $1.98 \mathrm{~m}$ and a simulated horizontal distance of $4.38 \mathrm{~m}$. The peak height reached / horizontal distance travelled by the mass centre for the same corresponding initial conditions were then maximized by varying the activation timings resulting in a peak height of $2.09 \mathrm{~m}$ and a horizontal distance of $4.67 \mathrm{~m}$. In a further two optimizations the initial conditions were interchanged giving a peak height of $1.78 \mathrm{~m}$ and a horizontal distance of $4.03 \mathrm{~m}$. The four optimized simulations show that even with similar approach speeds the initial conditions at touchdown have a substantial effect on the resulting performance. Whilst the takeoff phase is clearly important, unless the approach phase and the subsequent touchdown conditions are close to optimal then a jumper will be unable to compensate for touchdown condition shortcomings during the short takeoff phase to achieve a performance close to optimum.
\end{abstract}

Keywords: running jumps, initial conditions, takeoff technique

\section{Introduction}

Running jumps are an integral part of many activities and can be generally considered to consist of three main phases: the approach, the takeoff and the flight phase (Greig and Yeadon, 2000). The takeoff is considered to be the most important of the three phases while the approach phase is vital for its preparation (Dapena, 1988). The main purpose of the approach phase is therefore to place the athlete in the optimum initial conditions for the takeoff phase. Due to the specific requirements of high jumping and long jumping there are differences in athletes' optimal initial conditions. The optimal approach speed for long jumping is faster than for high jumping where an 'intermediate' approach speed is optimal (Greig and Yeadon, 2000; Alexander, 1990). Using a theoretical model, Alexander (1990) found that long jumping has a steeper optimum plant angle (the angle between the backward horizontal and the line joining the ankle and hip of the takeoff leg) than in high jumping where the optimum plant angle is closer to the horizontal. The shallower plant angle utilised by high jumpers facilitates the production of vertical velocity. The steeper plant angle utilised in long jumping allows the athlete to gain vertical velocity whilst maintaining a fast horizontal velocity (Hay, 1981). Theoretically a straight plant leg is optimal for both high jumping (Grieg and Yeadon, 2000) and long jumping (Seyfarth et al., 2000) and a greater backward lean of the trunk at touchdown is needed for high jumping (Dapena, 1988), while in long jumping the trunk angle is closer to vertical (Graham-Smith and Lees, 2005).

Differences primarily in initial conditions at touchdown lead to a shorter takeoff phase of around 120 ms for long jumping (Seyfarth et al., 2000; Bridgett and Linthorne, 2006) compared to a longer contact time of around $180 \mathrm{~ms}$ for high jumping (Aura and Vittasalo, 1989). During the takeoff phase high jumpers try to maximise gain in vertical velocity (Greig 
and Yeadon, 2000) while long jumpers attempt to develop vertical velocity whilst limiting the inevitable loss in horizontal velocity (van Don and Hay, 1994). The amount of knee flexion of the takeoff leg during the final contact phase has been identified as one of the factors that influence the production of vertical velocity (Dapena, 1980). In the high jump the knee joint flexes to an angle in the region of $133^{\circ}$ (Dapena, 1980) whereas in the long jump the knee flexes to approximately $140^{\circ}$ (Graham-Smith and Lees, 2005), although the effect of different approach speeds on knee kinematics in each type of jump is not clear.

It is clear that both the approach phase (initial conditions at touchdown) and the takeoff phase are critical for a successful performance of a running jump for height or distance. The relationship between these two phases is complex with it not being clear what effect changes in takeoff technique can have on performance for a particular combination of approach characteristics. The purpose of this study was to use a theoretical simulation model to investigate the relative effects of initial conditions and takeoff technique on running jumps for height and distance.

\section{Methods}

An international male high jumper of height $1.89 \mathrm{~m}$ and mass $82 \mathrm{~kg}$, with a personal competition best of $2.31 \mathrm{~m}$ was used as the subject in the study. The athlete gave informed consent for the procedures, which were carried out in accordance with the protocol approved by Loughborough University Ethical Advisory Committee. Ninety-five anthropometric measurements were taken on the athlete and segmental inertia parameters were calculated using the geometric inertia model of Yeadon (1990b). The athlete was requested to perform a high jumping and a long jumping performance with similar approach speeds. Both performances were recorded at a frequency of $200 \mathrm{~Hz}$ using two video cameras (50-Hz Sony digital Handycam VX1000 camera and a NAC high-speed HSV-400 video camera; Wilson et al., 2006). Fifteen body landmarks (wrist, elbow, shoulder, hip, knee, ankle and toe joint centres of both sides of the body, plus the centre of the head) were manually digitized and were reconstructed using the Direct Linear Transformation algorithm (Karara, 1980) with camera synchronisation effected using the digitised landmark data (Yeadon and King, 1999). The coordinate data and the inertia data were used to calculate the jumper's orientation and configuration angles throughout the movements, along with the mass centre velocity and whole-body angular momentum about the mass centre (Yeadon, 1990a, 1990c). The time histories of the orientation and configuration angles were fitted using quintic splines (Wood and Jennings, 1979) in order to obtain angle and angular velocity estimates throughout the movements. Although the recorded high jumping performance (Fosbury-flop) was threedimensional in many respects, the contact phase was essentially planar since the mean deviation from the vertical plane through the mass centre path was less than $5^{\circ}$.

A planar eight-segment forward dynamics computer simulation model (King et al., 2006) was used (Figure 1) for the foot contact phase in running jumps. The eight segments comprised foot, shank and thigh of the takeoff leg, thigh and shank + foot of the free leg, trunk + head, upper arm and lower arm + hand (representing both arms). Wobbling masses situated within the shank and thigh segments of the takeoff leg and trunk segment and the foot-ground interface were modelled using non-linear spring-damper systems. The viscoelastic parameters for this elite high jumper were determined previously in the study of Wilson et al. (2006). Torque generators, comprising rotational elastic and contractile elements in series, acted around five of the joints (ankle, knee and hip of the takeoff leg; hip of the free leg and shoulder) with extensors and flexors represented separately. The torque produced by a torque generator during a simulation was given by the product of the activation and the maximum voluntary joint torque function (of contractile element angle and angular 
velocity) based on a rotational equivalent of Hill's hyperbolic function and a second hyperbolic function for the eccentric phase. The parameters were determined from dynamometer measurements (King et al., 2006; Yeadon et al., 2006). The activation of each torque generator ranged from 0 to 1 throughout a simulation with the activation at a specific time specified by an activation time history profile. The activation profiles were defined using 6 parameters for the agonists of each joint and 5 parameters for the antagonists of each joint as described in King et al. (2006). The parameters defined the timing of onset of activation, the times to rise and fall between minimum and maximum activation and the levels of minimum and maximum activation. The elbow and free knee joint were driven using splined angle time histories of the recorded jumps.

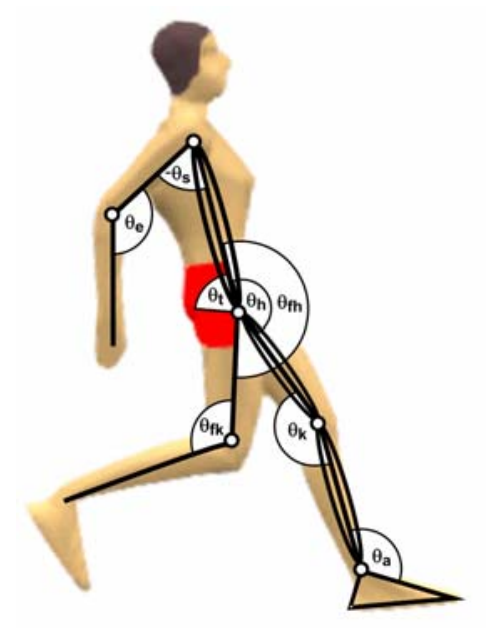

Figure 1. Eight segment simulation model. Rigid links between joint centres are shown as straight lines. Wobbling masses within the trunk and plant leg thigh and shank segments are shown with bounding arcs.

Input to the torque-driven model consisted of the kinematics at touchdown and the activation time histories of the 10 torque generators. Model output comprised the time histories of the foot-ground spring-damper displacements, joint angles and trunk orientation from which mass centre position and velocity together with angular momentum about the mass centre were calculated.

Two simulations which matched the recorded performances of the high jump and long jump during the foot contact prior to takeoff were obtained by varying the torque generator activation profiles in order to minimize the sum of a difference score and various penalties. The difference score for each simulation was the root mean square of six components based on the difference between simulation and performance in terms of (1) trunk orientation, (2) joint angles, (3) time of contact, (4) linear momentum, (5) angular momentum and (6) height / distance travelled in flight (King et al., 2006; Wilson et al., 2007). Penalties were used to ensure that the joint angles remained within anatomical limits. The peak height reached by the mass centre during the flight phase was determined using equations of constant acceleration under gravity along with the height and vertical velocity of the mass centre at takeoff. The horizontal distance travelled by the mass centre during flight was determined using the assumption that the mass centre had fallen to $0.6 \mathrm{~m}$ above the ground at the end of the jump based upon the experimental data collected.

Following the generation of matching simulations for the high jump (match $\mathrm{H}$ ) and the long jump (match $\mathrm{L}$ ) four optimizations were carried out. Using the initial conditions from the respective matching simulations the peak height reached by the mass centre in the high 
jump and the horizontal distance travelled by the mass centre during the flight phase in the long jump were maximized (opt $\mathrm{HH}$ and opt LL respectively) by varying the 55 torque activation parameters within the optimization algorithm Simulated Annealing (Corana et al., 1987). A further two optimizations were carried out in which the initial conditions from the matching simulation of the high jump were used in an optimization to maximize jump length (opt HL) and the initial conditions from the matching simulation of the long jump were used in an optimization to maximize jump height (opt LH). Perturbations to joint torque activation timings of the knee and hip were incorporated in the optimization process to ensure that a robust optimum solution was found in each case (Wilson et al., 2007). In particular, the onset timings of the hip and knee extensor torque generators were varied by $\pm 5 \mathrm{~ms}$ producing four additional simulations with the score maximized taken to be the mean score of the four perturbed simulations. In addition in all four optimizations the knee and ankle joint angles of the takeoff leg were constrained to be less than $180^{\circ}$ and $160^{\circ}$ respectively both at takeoff and during the first $100 \mathrm{~ms}$ of the flight phase assuming constant angular acceleration (Wilson et al., 2007).

\section{Results}

The recorded high jumping and long jumping performances had similar approach speeds of $7.4 \mathrm{~ms}^{-1}$ and $6.9 \mathrm{~ms}^{-1}$ respectively but different initial configuration and orientation angles at touchdown (Table 1, Figure 2). The different angles at touchdown resulted in a shallower plant angle of $53^{\circ}$ (from the backward horizontal) for the high jump compared to a plant angle of $60^{\circ}$ for the long jump.

Table 1. Initial conditions for matching simulations

\begin{tabular}{|c|c|c|c|c|c|}
\hline variable & high jump & long jump & variable & high jump & long jump \\
\hline$v_{\mathrm{cm} x}$ & $7.40 \mathrm{~ms}^{-1}$ & $6.87 \mathrm{~ms}^{-1}$ & $v_{\mathrm{cmy}}$ & $-0.58 \mathrm{~ms}^{-1}$ & $-0.43 \mathrm{~ms}^{-1}$ \\
\hline$\theta_{\mathrm{a}}$ & $85^{\circ}$ & $98^{\circ}$ & $\dot{\theta}_{\mathrm{a}}$ & $201^{\circ} \mathrm{s}^{-1}$ & $28^{\circ} \mathrm{s}^{-1}$ \\
\hline$\theta_{\mathrm{k}}$ & $157^{\circ}$ & $151^{\circ}$ & $\dot{\theta}_{\mathrm{k}}$ & $-58^{\circ} \mathrm{s}^{-1}$ & $-162^{\circ} \mathrm{s}^{-1}$ \\
\hline$\theta_{\mathrm{h}}$ & $141^{\circ}$ & $134^{\circ}$ & $\dot{\theta}_{\mathrm{h}}$ & $219^{\circ} \mathrm{s}^{-1}$ & $-28^{\circ} \mathrm{s}^{-1}$ \\
\hline$\theta_{\mathrm{S}}$ & $59^{\circ}$ & $-20^{\circ}$ & $\dot{\theta}_{\mathrm{S}}$ & $881^{\circ} \mathrm{s}^{-1}$ & $518^{\circ} \mathrm{s}^{-1}$ \\
\hline$\theta_{\mathrm{e}}$ & $92^{\circ}$ & $116^{\circ}$ & $\dot{\theta}_{\mathrm{e}}$ & $-1320^{\circ} \mathrm{s}^{-1}$ & $156^{\circ} \mathrm{s}^{-1}$ \\
\hline$\theta_{\mathrm{rh}}$ & $209^{\circ}$ & $197^{\circ}$ & $\dot{\theta}_{\mathrm{rh}}$ & $-228^{\circ} \mathrm{s}^{-1}$ & $-796^{\circ} \mathrm{s}^{-1}$ \\
\hline$\theta_{\mathrm{rk}}$ & $104^{\circ}$ & $127^{\circ}$ & $\dot{\theta}_{\mathrm{rk}}$ & $1271^{\circ} \mathrm{s}^{-1}$ & $-460^{\circ} \mathrm{s}^{-1}$ \\
\hline$\theta_{\mathrm{t}}$ & $80^{\circ}$ & $91^{\circ}$ & $\dot{\theta}_{\mathrm{t}}$ & $-46^{\circ} \mathrm{s}^{-1}$ & $49^{\circ} \mathrm{s}^{-1}$ \\
\hline
\end{tabular}

Note: See Figure 1 for angle definitions, $v_{\mathrm{cmx}}$ and $\mathrm{v}_{\mathrm{cmy}}$ are the horizontal and vertical velocities of the mass centre at touchdown. 


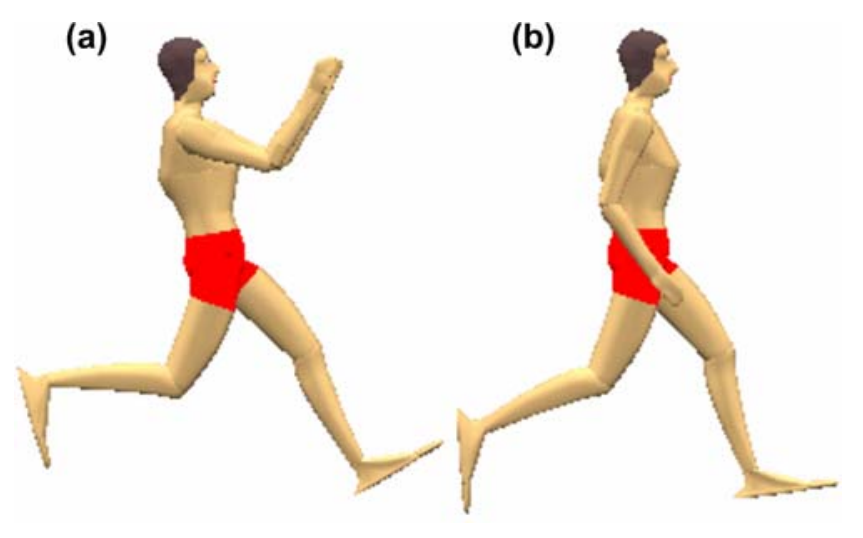

Figure 2. Orientation and configuration at touchdown for (a) the high jump and (b) the long jump performances.

The matching simulation of the high jump performance resulted in a peak height of 1.98 $\mathrm{m}$ compared to the recorded peak height of $2.01 \mathrm{~m}$, a difference score of $6.9 \%$ and a horizontal distance travelled of $3.91 \mathrm{~m}$ (Table 2, Table 3). The matching simulation of the long jump performance resulted in a horizontal distance travelled of $4.38 \mathrm{~m}$ compared to the recorded distance of $4.58 \mathrm{~m}$, a difference score of $10.5 \%$ and a peak height of $1.65 \mathrm{~m}$ (Table 2, Table 3). The torque activation profiles were similar for the two matching simulations (Figure 3) although the time to peak knee extensor activation was considerably shorter for match L compared to match H (0.051 s compared to 0.097 s) (Table 4).

Table 2. Details of the difference score for the matching simulations

\begin{tabular}{|c|c|c|}
\hline & match $\mathrm{H}$ & match L \\
\hline difference score & $6.9 \%$ & $10.5 \%$ \\
\hline trunk orientation & $7.7^{\circ}$ & $2.6^{\circ}$ \\
\hline joint angles & $13.1^{\circ}$ & $19.0^{\circ}$ \\
\hline contact time & $1.1 \%$ & $11.7 \%$ \\
\hline linear momentum & $6.4 \%$ & $11.4 \%$ \\
\hline angular momentum & $0.6 \%$ & $0.0 \%$ \\
\hline peak height & $4.0 \%$ & \\
\hline horizontal distance & & $4.3 \%$ \\
\hline
\end{tabular}


Table 3. Mass centre location $\left(\mathrm{CM}_{\mathrm{x}}, \mathrm{CM}_{\mathrm{z}}\right)$ at takeoff [m], horizontal and vertical velocities of the mass centre $\left(\mathrm{VCM}_{\mathrm{x}}, \mathrm{VCM}_{\mathrm{z}}\right)$ at takeoff $\left[\mathrm{ms}^{-1}\right.$ ] and the heights and distances jumped [m]

\begin{tabular}{|c|c|c|c|c|c|c|}
\hline & $\begin{array}{c}\text { match } \\
\mathrm{H}\end{array}$ & $\begin{array}{c}\text { match } \\
\text { L }\end{array}$ & $\begin{array}{c}\text { opt } \\
\mathrm{HH}\end{array}$ & $\begin{array}{c}\text { opt } \\
\text { LL }\end{array}$ & $\begin{array}{c}\text { opt } \\
\text { HL }\end{array}$ & $\begin{array}{c}\text { opt } \\
\text { LH }\end{array}$ \\
\hline $\mathrm{CM}_{\mathrm{x}}$ & 0.00 & 0.37 & 0.06 & 0.38 & -0.02 & 0.38 \\
\hline $\mathrm{CM}_{\mathrm{z}}$ & 1.28 & 1.20 & 1.27 & 1.25 & 1.29 & 1.24 \\
\hline $\mathrm{VCM}_{\mathrm{x}}$ & 4.30 & 5.72 & 4.02 & 5.61 & 4.27 & 5.45 \\
\hline $\mathrm{VCM}_{\mathrm{z}}$ & 3.71 & 2.98 & 4.00 & 3.30 & 3.91 & 3.37 \\
\hline height & 1.98 & 1.65 & 2.09 & 1.80 & 2.06 & 1.82 \\
\hline distance & 3.91 & 4.38 & 3.87 & 4.67 & 4.04 & 4.59 \\
\hline
\end{tabular}
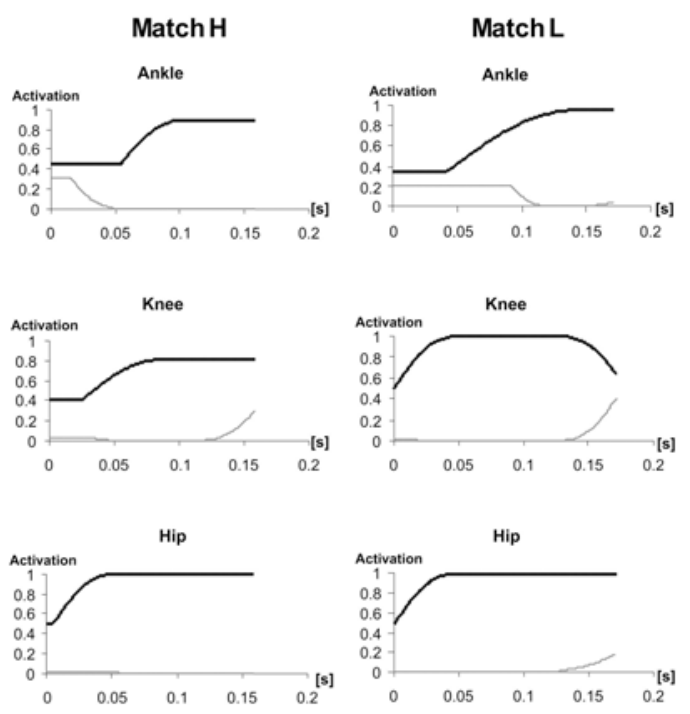

Figure 3. Activation time histories for the ankle, knee and hip extensors (black) and flexors (grey) in the matching simulations.

In opt $\mathrm{HH}$ the optimised peak height reached by the mass centre was $2.09 \mathrm{~m}$ which corresponded to an increase of $0.11 \mathrm{~m}$ from the matching simulation match $\mathrm{H}$. In opt LL the optimised horizontal distance travelled by the mass centre during the flight phase was $4.67 \mathrm{~m}$ which corresponded to an increase of $0.29 \mathrm{~m}$ from the matching simulation. Optimising for the opposite performance variable (opt LH and opt HL) had relatively small effects on the peak height $(0.02 \mathrm{~m})$ or horizontal distance travelled $(0.17 \mathrm{~m})$ by the mass centre during the flight phase (Table 3). The effect of the initial conditions was much larger than the effect of the changed torque generator activation technique with a $0.63 \mathrm{~m}$ greater distance travelled in opt LL compared with opt HL even though the approach speed was greater for opt HL (Table 3). The effect of the initial conditions was also greater than that of the takeoff technique for the time of contact, for the mass centre position at takeoff (Table 3), for the knee and hip angle time histories of the takeoff leg (Figure 4) and also the torque activation time histories (Table 4, Figure 5). In particular the time taken for the knee extensors to reach maximum activation was clearly a function of the initial conditions $(0.096 \mathrm{~s}$ for opt HH / opt HL compared to $0.050 \mathrm{~s}$ for opt LL / opt LH). The hip extensor activation time history was largely independent of both initial conditions and takeoff technique in the four optimised simulations (Table 4, Figure 5). Furthermore, the knee angle time histories for the two 
optimal jumps for height (opt $\mathrm{HH}$ and opt LH) had less knee flexion than the equivalent optimal simulation for distance (opt LL and opt HL) with the same initial conditions (Figure 4).

Table 4. Time to maximal activation of the leg joint extensor torque generators

\begin{tabular}{|c|c|c|c|c|c|c|}
\cline { 2 - 7 } \multicolumn{1}{c|}{} & \multicolumn{6}{c|}{ time to maximal activation [s] } \\
\cline { 2 - 7 } \multicolumn{1}{c|}{} & $\begin{array}{c}\text { match } \\
\mathrm{H}\end{array}$ & $\begin{array}{c}\text { match } \\
\mathrm{L}\end{array}$ & $\begin{array}{c}\text { opt } \\
\text { HH }\end{array}$ & $\begin{array}{c}\text { opt } \\
\text { LL }\end{array}$ & $\begin{array}{c}\text { opt } \\
\text { HL }\end{array}$ & $\begin{array}{c}\text { opt } \\
\text { LH }\end{array}$ \\
\hline $\begin{array}{c}\text { ankl } \\
\text { e }\end{array}$ & 0.106 & 0.154 & 0.111 & 0.141 & 0.120 & 0.122 \\
\hline knee & 0.097 & 0.051 & 0.096 & 0.050 & 0.096 & 0.050 \\
\hline hip & 0.054 & 0.051 & 0.055 & 0.050 & 0.053 & 0.051 \\
\hline
\end{tabular}
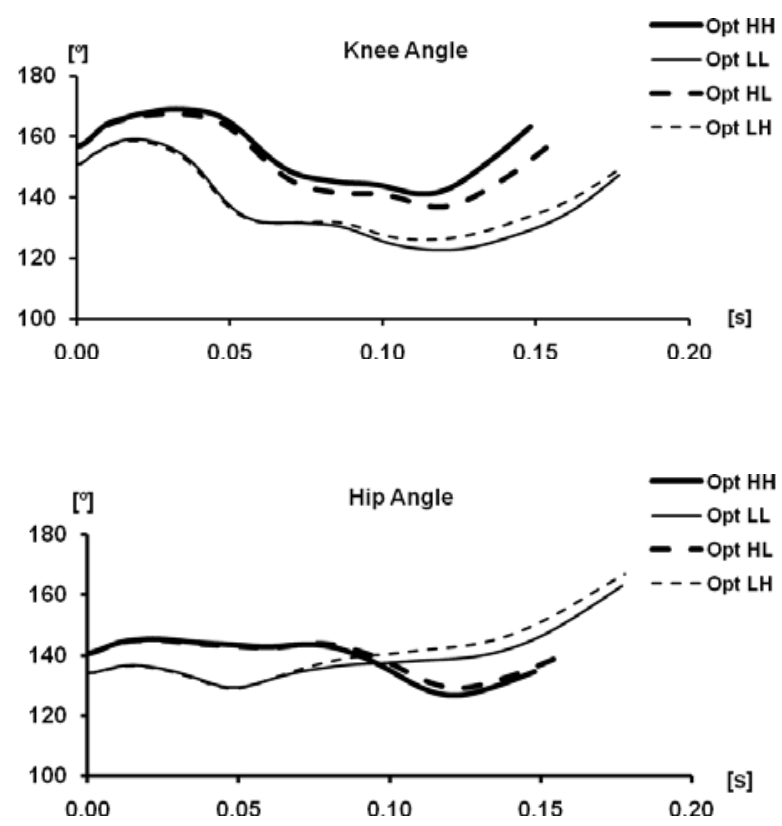

Figure 4. Joint angle time histories of the knee and hip for the four optimised simulations. Initial conditions from the high jump and long jump performances are shown with thick and thin lines respectively and the solid lines correspond to opt $\mathrm{HH}$ and opt LL, while the dashed lines correspond to opt HL and opt LH. 

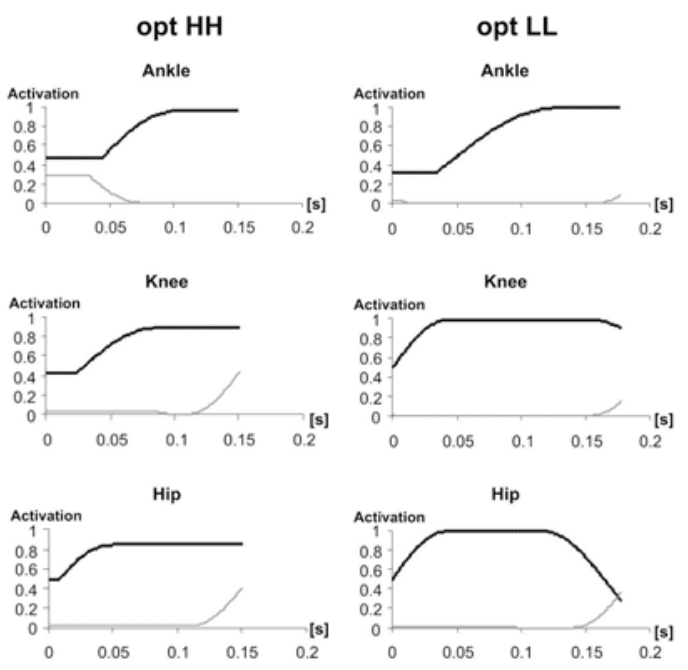

[b]
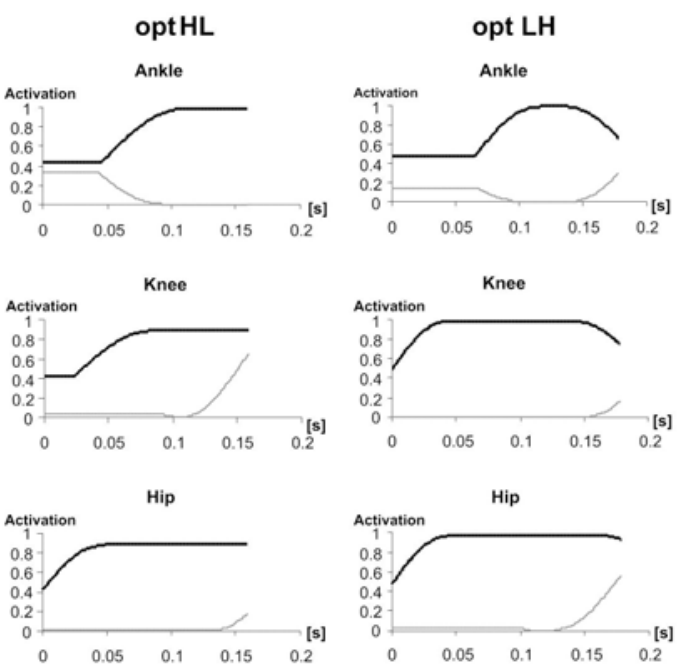

Figure 5. Activation time histories for the ankle, knee and hip extensors (black) and flexors (grey) in (a) the optimisations for height (opt $\mathrm{HH}$ ) and distance (opt $\mathrm{LL}$ ) with the initial conditions for high and long jumps and (b) the optimisations for length (opt HL) and height (opt LH) with the initial conditions for high and long jumps.

\section{Discussion}

The aim of this study was to investigate the relative effects of initial conditions and takeoff technique on running jumps for height and distance. A planar eight segment subjectspecific computer simulation model was used to simulate running jumps for height and distance with two different sets of initial touchdown conditions and determine robust optimal solutions for height and distance. Overall the effect of initial conditions was much greater than the takeoff technique on the heights reached and distances jumped. The heights and distances achieved in the optimised jumps (opt HH and opt LL) were $0.11 \mathrm{~m}$ and $0.29 \mathrm{~m}$ greater than the respective matching simulations suggesting that for the given initial conditions the techniques used by the elite high jumper were relatively close to optimal.

The two jumping performances used similar approach speeds but different initial configuration and orientation angles at ground contact (Table 1). The different angles at touchdown resulted in a shallower plant angle of $53^{\circ}$ (from the backward horizontal) for the high jump compared to a plant angle of $60^{\circ}$ for the long jump. The steeper angle used for the 
long jumping performance agrees well with previous studies (Alexander, 1990; Hay, 1981) and suggests that the elite high jumper used in this study had appropriate initial conditions for the two jumps. Furthermore, the trunk orientation at touchdown was closer to vertical in the long jumping performance which is in agreement with previous studies (Dapena, 1988; Graham-Smith \& Lees, 2005) where a backward lean at touchdown in the high jump has previously been identified as being advantageous to performance (Dapena, 1988). The clear differences in initial configuration / orientation angles between the two performances and agreement with the literature suggests that the elite high jumper used in this study was able to adopt a close to optimal position at touchdown for each jump while being restricted to use similar horizontal approach speeds. As a consequence it would be expected that even with optimal technique during the takeoff phase it would not be possible to compensate for inappropriate initial conditions when the initial conditions were interchanged (opt HL and opt LH).

The effect of takeoff technique was investigated by keeping the initial conditions fixed and optimising for the alternative performance outcome (opt HL and opt LH). Small effects (Table 3) of less than $0.06 \mathrm{~m}$ and $0.17 \mathrm{~m}$ difference in the optimal solutions for peak height jumped / distance travelled between opt $\mathrm{HH}$ - opt HL and opt LL - opt LH were found. This result confirms that although the takeoff phase is important, it is not possible to make up for inappropriate initial conditions by changing technique. In addition, during the takeoff phase and in contrast to previous literature (Dapena, 1980; Graham-Smith \& Lees, 2005), the knee flexed to a greater degree in the optimised long jumping performance (opt LL) compared to the optimised high jumping performance (opt HH) (Figure 4). The reason for the discrepancy may be the approach speeds used in the two optimal simulations were similar when in reality the approach speed used in long jumping is normally considerably faster than in high jumping (Alexander, 1990). In the current study, comparing opt HH with opt HL and opt LL with opt LH also showed that both optimal simulations for height (with the same approach speed as the optimised simulations for distance) had slightly less knee flexion than the two optimal simulations for distance.

The effect of the initial conditions was investigated by comparing the two optimal solutions for height with different initial conditions (opt $\mathrm{HH}$ and opt $\mathrm{LH}$ ) and the two optimal solutions for distance with different initial conditions (opt LL and opt HL). Both comparisons showed the same trend that the initial conditions were crucial to a successful performance with a $0.27 \mathrm{~m}$ difference in jump height (opt $\mathrm{HH}$ and opt $\mathrm{LH}$ ) and a $0.63 \mathrm{~m}$ difference in distance jumped (opt LL and opt HL). Consequently to achieve an optimal performance requires an appropriate set of initial conditions at touchdown. The effect of the initial conditions was also evident in the mass centre position at takeoff (Table 3) with the initial conditions for a high jump giving a mass centre position vertically above the foot for match $\mathrm{H}$, opt $\mathrm{HH}$ and opt HL, while the initial conditions for a long jump resulted in a mass centre position at takeoff of approximately $0.38 \mathrm{~m}$ in front of the toes of the takeoff leg for match $\mathrm{L}$, opt LL and opt LH. This is in agreement with a previous study (Nagano et al., 2007) where in jumps for height the mass centre was above the feet at takeoff, but some distance in front of the feet for jumps for distance and confirms that there is little that can be done during the short contact phase to effect the path of the mass centre during the takeoff phase for a given set of initial conditions at touchdown.

The general applicability of the study is potentially limited by the use of a single elite subject and two performances: a running jump for height and a running jump for distance with similar approach speeds. However, the two performances in terms of initial configurations and orientation have been shown to be consistent with previous studies and have resulted in distinct optimal solutions for height and distance. In conclusion, the results 
of this study suggest that it is the differences in initial conditions rather than takeoff technique which have the greater influence on optimal jumping performance. It is suggested that this is due to the distinct differences in optimal initial conditions between the two jumps and the relatively short period of time in which the takeoff technique can be adjusted to accommodate for changes in optimal initial conditions. Whilst the takeoff phase is clearly important for the successful performance of a jump and could be considered to be the most important of the three phases of jumping, if the approach phase and the subsequent initial conditions are not close to optimal then a jumper will be unable to compensate for these shortcomings during the short takeoff phase to achieve a jump height or jump distance close to optimum.

\section{References}

Alexander, R. McN., 1990. Optimum take-off techniques for high jumps and long jumps. Philosophical Transactions of the Royal Society of London B 329, 3-10.

Aura, O., Viitasalo, J.T. 1989. Biomechanical characteristics of jumping. International journal of Sports Biomechanics, 5, 89-98.

Bridgett, L.A., Linthorne, N.P. 2006. Changes in long jump take-off technique with increasing run-up speed. Journal of Sports Sciences, 24, 889-897.

Corana, A., Marchesi, M., Martini, C., Ridella, S., 1987. Minimising multimodal functions of continuous variables with the "simulated annealing" algorithm. ACM Transactions on Mathematical Software 13, 262-280.

Dapena, J. 1980. Mechanics of translation in the fosbury-flop. Medicine and Science in Sports and Exercise 12, 37-44.

Dapena, J. 1988. Biomechanical analysis of the fosbury flop. Track Technique 104, 33073317.

van Don, B., Hay, J.G. 1994. Velocity and angular momentum interactions during the takeoff in the long jump. In Blankevoort, L. and Kooloos, J.G.M. (Eds.). Proceedings of the Second World Congress in Biomechanics (p. 254), July 10-15, Amsterdam, The Netherlands.

Graham-Smith, P., Lees, A. 2005. A three-dimensional kinematic analysis of the long jump take-off. Journal of Sports Sciences 23, 891-903.

Greig, M.P. and Yeadon, M.R. 2000. The influence of touchdown parameters on the performance of a high jumper. Journal of Applied Biomechanics 16, 367-378.

Hay, J.G. 1981. Fundamental mechanics of jumping. In Gambetta, V. (Ed.), Track and field coaching manual (pp. 148-154). New York: Leisure Press.

Karara, H.M., 1980. Non-metric cameras. In Atkinson, K. B. (Ed.), Developments in close range photogrammetry -1 (pp. 63-80). Applied Science Publishers, London.

King, M.A., Wilson, C., Yeadon, M.R., 2006. Evaluation of a torque-driven model of jumping for height. Journal of Applied Biomechanics 22, 1-11.

Nagano, A., Komura, T., Fukashiro, S., 2007. Optimal coordination of maximal-effort horizontal and vertical jump motions - a computer simulation study. Biomedical Engineering Online, 6:20.

Seyfarth, A., Blickhan, R., Van Leeuwen, J.L. 2000. Optimum take-off techniques and muscle design for long jump. Journal of Experimental Biology, 203, 741 - 750.

Wilson, C., Yeadon, M.R., King, M.A., 2006. Determination of subject-specific model parameters for visco-elastic elements. Journal of Biomechanics 39, 1883-1890.

Wilson, C., Yeadon, M.R. and King, M.A. 2007. Considerations that affect optimised simulation in a running jump for height. Journal of Biomechanics 40, 3155-3161. 
Wood, G.A., Jennings, L.S., 1979. On the use of spline functions for data smoothing. Journal of Biomechanics 12, 447-479.

Yeadon, M.R., 1990a. The simulation of aerial movement - I: The determination of orientation angles from film data. Journal of Biomechanics 23, 59-66.

Yeadon, M.R., 1990b. The simulation of aerial movement - II: A mathematical inertia model of the human body. Journal of Biomechanics 23, 67-74.

Yeadon, M.R., 1990c. The simulation of aerial movement - III: The determination of the angular momentum of the human body. Journal of Biomechanics 23, 75-83.

Yeadon, M.R., King, M.A., 1999. A method for synchronising digitised video data. Journal of Biomechanics 32, 983-986.

Yeadon, M.R., Wilson, C., King, M.A., 2006. Modelling differential activation of knee joint extensors. Journal of Biomechanics 39, 476-482. 